\title{
Social skills measurement of the mentally impaired
}

\author{
WILLIAM B. WOLFOLK and DONALD FUCCI \\ Ohio University, Athens, Ohio \\ JULIE FRIEDENBERG GELZAYD \\ St. Joseph's Mercy Hospital, Ann Arbor, Michigan \\ and \\ CARRIE CONLEN MANZ \\ Rehabilitation Network, Birmingham, Michigan
}

\begin{abstract}
The purpose in the present study was to measure certain social skills of 6 mentally impaired adult subjects $(M$ age $=37.66$ years, age range $=19-57$ years). A preestablished protocol was used to assess pragmatic skills. Behaviors were judged to be appropriate, inappropriate, or unobserved for a controlled social situation. Behaviors that emerged were judged to be similar to those of language-disordered children described by Prutting and Kirchner (1987), who developed the protocol employed in this study. Intelligence quotients previously obtained for the 6 participants allowed appropriate prediction of the observed behaviors that constituted the subjects' pragmatic performance.
\end{abstract}

The evaluation of mentally impaired individuals necessarily involves consideration of their social performance. Impaired individuals are generally less accepted than their nonhandicapped peers (Morrison \& Borthwick, 1983). Normally accepted members of society view the communicative, social behaviors of the developmentally disabled as being crude or embarrassing.

Social interpersonal skills (pragmatics) have been highlighted as a major impediment to adult adjustment on the part of the mentally impaired. Schloss and Schloss (1985) defined social interpersonal skills to include eye contact, facial expression, posture, intonation, loudness, speech latency, enunciation, message content, speaking rate, motor/gestural, and verbal/vocal responses. These social skills encompass verbal, paralinguistic, and nonverbal aspects of communication. Social competence involving these skills implies that the individual is able to discern relevant social cues and behave in a manner that maximizes the probability of positive social interaction (Schloss \& Schloss, 1985).

A protocol developed by Prutting (1982), consisting of 30 pragmatic aspects of language, extrapolated from child language developmental literature, was designed to provide an overall clinical appraisal of the social skills of school-age children, adolescents, and adults. Samples of conversational interaction were assessed, and each aspect of the protocol was judged to be appropriate, inappropriate, or not observed. Prutting and Kirchner (1987) tested

Correspondence should be addressed to William B. Wolfolk, School of Hearing and Speech Sciences, Lindley Hall 201, Ohio University, Athens, OH 45701. the utility of the protocol for evaluating a range of pragmatic parameters in speech samples obtained from six diagnostic groups: normal children, normal adults, children with articulation disorders, children with language disorders, adults with left hemisphere damage, and adults with right hemisphere damage.

In the present study, the pragmatic deficits of 6 mentally disabled adults were described through the use of the Prutting and Kirchner (1987) profile. These results were then compared with obtained intelligence quotients, in order to answer the following questions: (1) Would the pragmatic parameters reported by Prutting and Kirchner be characteristically appropriate or inappropriate in the appraisal of developmentally disabled subjects? (2) Would the subjects be described by profiles similar to those noted in the Prutting and Kirchner study? (3) Is there a relationship between intelligence and pragmatic skill levels in developmentally disabled individuals?

\section{METHOD}

Subjects

Six mentally impaired adults served as subjects for this study. The subjects consisted of the following: Subject 1, a 33-year-old female with an IQ of 25; Subject 2, a 46-year-old female with an IQ of 32; Subject 3, a 57-year-old female with an IQ of 50; Subject 4, a 39-year-old female with an IQ of 53; Subject 5, a 19-year-old male with an IQ of 76; and Subject 6, a 32-year-old female with an IQ of 78. All 6 subjects had the verbal skills needed for assessment of their pragmatic skill behaviors.

\section{Materials}

The pragmatic protocol developed by Prutting (1982) was used by the authors of this study to describe the overall communicative ability of the $\mathbf{6}$ developmentally disabled subjects. The details of this protocol, along with definitions of the verbal, paralinguistic, and nonverbal pa- 
Table 1

Pragmatic Parameters Marked Inappropriate for 6 Mentally Impaired Adults

\begin{tabular}{|c|c|c|c|c|c|c|}
\hline \multirow[b]{2}{*}{ Parameter } & \multicolumn{6}{|c|}{ Subject/IQ } \\
\hline & $1 / 25$ & $2 / 32$ & $3 / 50$ & $4 / 53$ & $5 / 76$ & $6 / 78$ \\
\hline \multicolumn{7}{|c|}{ Verbal Aspects } \\
\hline Speech act pair analysis & & & $\mathbf{X}$ & & & \\
\hline Variety of speech acts & & & $\mathbf{X}$ & & & \\
\hline Topic selection & & & $\mathbf{X}$ & & & \\
\hline Topic introduction & & & $\mathbf{X}$ & & & \\
\hline \multicolumn{7}{|l|}{ Topic maintenance } \\
\hline Topic change & & & $\mathbf{X}$ & & & \\
\hline Turn-taking initiation & & & $\mathbf{X}$ & & & \\
\hline Turn-taking response & & & $\mathbf{X}$ & $\mathbf{X}$ & & \\
\hline Turn-taking repair/revision & & & $\mathbf{X}$ & & & \\
\hline Turn-taking pause time & & $\mathbf{X}$ & & & & $\mathbf{X}$ \\
\hline Turn-taking interruption/overlap & & $\mathbf{X}$ & $\mathbf{X}$ & & & \\
\hline Turn-taking feedback to speaker & $\mathbf{X}$ & $\mathbf{X}$ & $\mathbf{X}$ & & & \\
\hline Turn-taking adjacency & & $\mathbf{X}$ & $\mathbf{X}$ & & & \\
\hline Turn-taking contingency & $\mathbf{X}$ & $\mathbf{X}$ & $\mathbf{X}$ & & & \\
\hline Turn-taking quantity/conciseness & & $\mathbf{X}$ & $\mathbf{X}$ & & & \\
\hline Specificity/accuracy & & & $\mathbf{X}$ & $\mathbf{X}$ & & \\
\hline Cohesion & & $\mathbf{X}$ & $\mathbf{X}$ & $\mathbf{X}$ & & \\
\hline Varying communicative style & $\mathbf{X}$ & $\mathbf{X}$ & $\mathbf{X}$ & & & \\
\hline \multicolumn{7}{|c|}{ Paralinguistic Aspects } \\
\hline Intelligibility & $\mathbf{X}$ & $\mathbf{X}$ & & $\mathbf{X}$ & $\mathbf{X}$ & \\
\hline Vocal intensity & $\mathbf{X}$ & $\mathbf{X}$ & & & & \\
\hline Vocal quality & & & & & $\mathbf{X}$ & $\mathbf{X}$ \\
\hline Prosody & $\mathbf{X}$ & & $\mathbf{X}$ & & $\mathbf{X}$ & $\mathbf{X}$ \\
\hline Fluency & & & & & & $\mathbf{X}$ \\
\hline \multicolumn{7}{|c|}{ Nonverbal Aspects } \\
\hline Physical proximity & & $\mathbf{X}$ & & & & \\
\hline Physical contacts & & $\mathbf{X}$ & & & & \\
\hline Body posture & & $\mathbf{X}$ & & & & \\
\hline Foot/leg and hand/arm movements & & $\mathbf{X}$ & & & & \\
\hline Gestures & & & & & & \\
\hline Facial expression & & & & & & \\
\hline Eye gaze & & & & & & \\
\hline
\end{tabular}

rameters assessed, can be referred to in the original study of Prutting and Kirchner (1987).

\section{Procedure}

The subjects were observed during spontaneous 15 -min interactions with each other, other friends, or staff within group residential or vocational workshop settings. Observation, tape recordings, and written comments were used to ensure accurate scoring. Observed behaviors were judged to be appropriate or inappropriate according to examples provided by Prutting and Kirchner (1987).

\section{RESULTS AND DISCUSSION}

The overall pragmatic profile for the mentally impaired subjects utilized in the present study is shown in Table 1 . As was the case with the results of Prutting and Kirchner (1987), the subjects in this study did not present a definitive profile of pragmatic deficits based on their diagnostic label. The overall pattern of inappropriate behaviors exhibited by the mentally impaired subjects was located within the verbal aspects section of the protocol, which showed that the social behaviors of the mentally impaired group closely resembled those of a group of language- disordered children. The parameters most inappropriate for this group included turn-taking feedback to speaker, turn-taking contingency, cohesion, and varying communicative styles. Paralinguistically, inappropriate speech intelligibility was exhibited along with inappropriate prosody. Few inappropriate nonverbal behaviors were noted.

The subjects' IQs appeared to allow for prediction of expected pragmatic performance. Subjects 1, 2, and 3, whose IQ scores ranged from 25 to 50 , exhibited more inappropriate behaviors than did Subjects 4, 5, and 6, whose IQs were higher.

The pragmatic protocol employed in this study was a helpful index for assessing the social skill behaviors of the 6 mentally impaired subjects. It is not a standardized diagnostic test, however, and it must be used with caution. The protocol provided an understanding of the social functioning of the 6 subjects. As pointed out by Prutting and Kirchner (1987), it could be a useful tool for remediation, especially when intervention promoting social competence would most likely have an impact on the "quality of life" of mentally impaired individuals (Schloss \& Schloss, 1985). 


\section{REFERENCES}

MoRRISON, G. M., \& BorThwick, S. (1983). Patterns of behavior, cognitive competence, and social status for educable mentally retarded children. Journal of Special Education, 17, 441-451.

PRUTTING, C. A. (1982). Observational protocol for pragmatic behaviors (Clinic manual). Santa Barbara, CA: University of California Speech and Hearing Clinic.
Prutting, C. A., Kirchner, D. M. (1987). A clinical appraisal of the pragmatic aspects of language. Journal of Speech \& Hearing Disorders, 52, 105-119.

Schloss, P. J., \& Schloss, C. N. (1985). Contemporary issues in social skills research with mentally retarded persons. Journal of Special Education, 19, 269-282.

(Manuscript received November 17, 1990.) 